\title{
The European Spallation Source in a personal view for the German Colloid and Soft Matter Society
}

\author{
Henrich Frielinghaus ${ }^{1}$ \\ Published online: 10 March 2020 \\ (C) The Author(s) 2020
}

The German Colloid Society had its annual meeting in September 23-25, 2019, at the University of Stuttgart. Many interesting contributions employing neutron scattering as an important method were presented. From that, often discussions came up after the talks and in the coffee breaks which role the European Spallation Source (ESS) in Lund, Sweden, will play in the context of colloid and soft matter research. After that, I tried to condense some thoughts and my own opinions with the background as an active researcher thoroughly employing neutron scattering. The first 15 instruments of the ESS are presented in Ref. [1]. Future instrumentation rounds are foreseen in the near future.

The two small-angle neutron scattering (SANS) instruments LoKI and SKADI will be flagships in the discussed context, because they will be addressed in the first place due to their resolved length scales in the approximate range of 1 to $1000 \mathrm{~nm}$. Here, the structure of mesoscales will be resolved that are often the origin of understanding the functionality of colloidal and soft matter materials on the macroscopic length scales. Of course, this method is often combined with further characterizations be it laboratory scale methods or further scattering methods. One important example is the microemulsion $[2,3]$ that structure needs to be resolved in combination with further methods for a wider range of purposes. Especially, when taking supercritical $\mathrm{CO}_{2}$ as the oil [3], new perspectives for industrial nano-foams are opened. The instrument LoKI will focus on a broader Q-range at slightly

Henrich Frielinghaus

h.frielinghaus@fz-juelich.de

1 Forschungszentrum Jülich GmbH, Jülich Center for Neutron Science at Heinz Maier-Leibnitz Zentrum, Lichtenbergstrasse 1, 85747 Garching, Germany worse resolution, while SKADI is the multi-purpose SANS with higher resolution. The latter instrument will also aim at magnetic nano-particles [4] using polarization and polarization analysis.

The engineering instruments BEER and HEIMDAL serve also for much higher $Q$ with a compromise in the SANS range where lowest $\mathrm{Q}$ are cut. However, this large Q-range is interesting for crystallizing materials, such as polymeric membranes for fuel and electrolyzer cells [5, 6]. In operando studies are highly interesting for studying the conversion mechanisms and fatigue in the membrane.

The diffraction instrument NMX is originally devoted to hydrogen detection in protein crystals. However, well-ordered lipid bilayer systems can be characterized also in terms of structure $[7,8]$ at this instrument. The influence of drugs and proteins on the bilayer structure is usually analyzed in such experiments. Very crucial is the radiation background if the weakest peaks are to be detected.

The reflectometer FREIA simultaneously measures the specular reflectivity in a wide Q-range. This is for instance interesting for microgels [9] and lipid bilayers (partially from whole cells) [10]. A wider use towards grazing incidence SANS is not foreseen in the current state.

Currently, the spectrometers MIRACLES and CSPEC serve for the medium and higher energies in soft matter research. Examples focus on nano-particles in a viscous environment [11], and also proteins are often in the focus [12].

Highly important are the joint efforts of the European DEUNET network in deuteration on demand (https:// sine2020.eu/about/the-road-to-the-ess/deunet.html) that serves for lipids [13], polymers, and other smaller molecules needed in colloid and soft matter science. A successor program is planned within the framework of the League of advanced European Neutron Sources (LENS) (https://www. lens-initiative.org). 
The uncovered types of instruments that are urgently needed at the ESS are a grazing incidence (GI)SANS instrument and a conventional neutron spin echo (NSE) spectrometer. The GISANS instrument allows for studying lateral structures in thin films at length scales of a typical SANS instrument [14, 15]. Varying the incident angle, different depths are highlighted independent of the lateral resolution. The Swedish community is currently preparing for a GISANS instrument proposal. However, the detailed plans and a final decision are still in preparation. Similarly, a conventional NSE spectrometer [16, 17] completes the spectrometer suite of the ESS towards the time resolution of $1 \mathrm{~ns}$ to a few $100 \mathrm{~ns}$. This method is essential in the colloid and soft matter research in the field of polymers, micelles, microgels, proteins, and lipid bilayers for instance [18]. If the radiation background is low, grazing incidence NSE spectroscopy [19] could be implemented to this instrument which directly leads us to tribology effects and the dynamics of membrane proteins. Both instruments (GISANS and GINSE) would complement each other when aiming at near-surface kinetics and dynamics, possibly in operando. This would further be highly interesting when studying lithium batteries, fuel and electrolyzer cells, and film deposition to name some of them. These two rather new methods tease the new source ESS in terms of intensity because the scattering volumes are tiny. Apart from that, lowest radiation background is inevitable when detecting low signals. After all, surprising and profitable new results can be expected from the two instruments. So, I hope that these considerations would feed in to the decisions of the next set of instruments to be built at the ESS and the necessary funding will be raised.

Funding Information Open Access funding provided by Projekt DEAL.

Open Access This article is licensed under a Creative Commons Attribution 4.0 International License, which permits use, sharing, adaptation, distribution and reproduction in any medium or format, as long as you give appropriate credit to the original author(s) and the source, provide a link to the Creative Commons licence, and indicate if changes were made. The images or other third party material in this article are included in the article's Creative Commons licence, unless indicated otherwise in a credit line to the material. If material is not included in the article's Creative Commons licence and your intended use is not permitted by statutory regulation or exceeds the permitted use, you will need to obtain permission directly from the copyright holder. To view a copy of this licence, visit http://creativecommons.org/licenses/by/4.0/.

\section{References}

1. Andersen KH, Argyriou DN, Jackson AJ, Houston J, Henry PF, Deen PP et al (2020) The instrument suite of the European
Spallation Source. Nucl Instr Meth Phys Res A 957:163402. https://doi.org/10.1016/j.nima.2020.163402

2. Deimling M, Kirchhof M, Schwager B, Qawasmi Y, Savin A, Mühlhäuser T, Frey W, Claasen B, Baro A, Sottmann T, Laschat S (2019) Asymmetric catalysis in liquid confinement: probing the performance of novel chiral rhodium-diene complexes in microemulsions and conventional solvents. Chemistry - Europ J 25:9464-9476. https://doi.org/10.1002/chem.201900947

3. Kunze L, Tseng SY, Schweins R, Sottmann T, Frey H (2019) Nonionic aliphatic polycarbonate diblock copolymers based on $\mathrm{CO}_{2}$, 1, 2-butylene oxide, and mPEG: synthesis, micellization, and solubilization. Langmuir 35:5221-5231. https://doi.org/10. 1021/acs.langmuir.8b04265

4. Zaloga J, Feoktystov A, Garamus VM, Karawacka W, Ioffe A, Brückel T, Tietze R, Alexiou C, Lyer S (2018) Studies on the adsorption and desorption of mitoxantrone to lauric acid/albumin coated iron oxide nanoparticles. Coll. Surf. B: Biointerf. 161:1826. https://doi.org/10.1016/j.colsurfb.2017.09.057

5. Ueda S, Koizumi S, Tsutsumi Y (2019) Flooding and performance of polymer electrolyte fuel cell, investigated by small-angle neutron scattering, neutron radiography and segmented electrode. Results in Phys 12:504-511. https://doi.org/10.1016/j.rinp.2018.11.082

6. Holderer O, Carmo M, Shviro M, Lehnert W, Noda Y, Koizumi S, Appavou MS, Appel M, Frielinghaus H (2020) Fuel cell electrode characterization using neutron scattering. Materials, MDPI submitted

7. Bremer A, Kent B, Hauß T, Thalhammer A, Yepuri NR, Darwish TA, Garvey CJ, Bryant G, Hincha DK (2017) Intrinsically disordered stress protein COR15A resides at the membrane surface during dehydration. Biophys J 113:572-579. https://doi.org/10.1016/j. bpj.2017.06.027

8. Eichner A, Stahlberg S, Sonnenberger S, Dobner B, Ostermann A, Schrader TE, Hauß T, Schroeter A, Huster D, Neubert RHH (2017) Influence of the penetration enhancer isopropyl myristate on stratum corneum lipid model membranes revealed by neutron diffraction and ${ }^{2} \mathrm{H}$ NMR experiments. Biochim Biophys Acta Biomembr 1859:745-755. https://doi.org/10.1016/j.bbamem.2017.01.029

9. Kyrey T, Witte J, Pipich V, Feoktystov A, Koutsioubas A, Vezhlev E, Frielinghaus H, Klitzing Rv, Wellert S, Holderer O (2019) Influence of the cross-linker content on adsorbed functionalized microgel coatings. Polymer 169:29-35. https://doi.org/10.1016/j. polymer.2019.02.037

10. Böhm P, Koutsioubas A, Moulin JF, Rädler JO, Sackmann E, Nickel B (2018) Probing the interface structure of adhering cells by contrast variation neutron reflectometry. Langmuir 35:513-521. https://doi.org/10.1021/acs.langmuir.8b02228

11. Weidner MC, Evenson Z, Zamponi M, Possart W (2019) Molecular motion in viscous DGEBA with nanoparticles as seen by quasielastic neutron scattering. Macromol Chem Phys 220:1800275. https://doi.org/10.1002/macp.201800275

12. Sarter M, Niether D, Koenig BW, Lohstroh W, Zamponi M, Jalarvo NH, Wiegand S, Fitter J, Stadler AM (2020) Strong adverse contribution of conformational dynamics to streptavidin-biotin binding. J Phys Chem B 124:324-335. https://doi.org/10.1021/acs.jpcb. $9 \mathrm{~b} 08467$

13. Bryant G, Taylor MB, Darwish TA, Krause-Heuer AM, Kent B, Garvey CJ (2019) Effect of deuteration on the phase behaviour and structure of lamellar phases of phosphatidylcholines-deuterated lipids as proxies for the physical properties of native bilayers. Coll Surf B: Biointerf 177:196-203. https://doi.org/10.1016/j. colsurfb.2019.01.040 
14. Müller-Buschbaum P (2013) Grazing incidence small-angle neutron scattering: challenges and possibilities. Polym J 45:34-42. https://doi.org/10.1038/pj.2012.190

15. Wolff M (2018). EPJ Web of Conferences 188:04002. https://doi. org/10.1051/epjconf/201818804002

16. Ohl M, Monkenbusch M, Arend N, Kozielewski T, Vehres G, Tiemann C, Butzek M, Soltner H, Giesen U, Achten R, Stelzer H, Lindenau B, Budwig A, Kleines H, Drochner M, Kaemmerling P, Wagener M, Möller R, Iverson EB, Sharp M, Richter D (2012) The spin-echo spectrometer at the Spallation Neutron Source (SNS). Nucl. Instr. Meth. Phys. Res. A 696:85-99. https://doi.org/10. 1016/j.nima.2012.08.059

17. Pasini S, Holderer O, Kozielewski T, Richter D, Monkenbusch M (2019) J-NSE-Phoenix, a neutron spin-echo spectrometer with optimized superconducting precession coils at the MLZ in Garching. Rev scient Instr 90:043107. https://doi.org/10.1063/1.5084303

18. Sakai VG, Arbe A (2009) Quasielastic neutron scattering in soft matter. Curr Opin Coll Interf Sci 14:381-390. https://doi.org/10. 1016/j.cocis.2009.04.002

19. Frielinghaus H, Gvaramia M, Mangiapia G, Jaksch S, Ganeva M, Koutsioubas A, Mattauch S, Ohl M, Monkenbusch M, Holderer O (2017) New tools for grazing incidence neutron scattering experiments open perspectives to study nano-scale tribology mechanisms. Nucl. Instr. Meth. Phys. Res. A 871:72-76. https://doi.org/10.1016/ j.nima.2017.07.064
Publisher's note Springer Nature remains neutral with regard to jurisdictional claims in published maps and institutional affiliations.

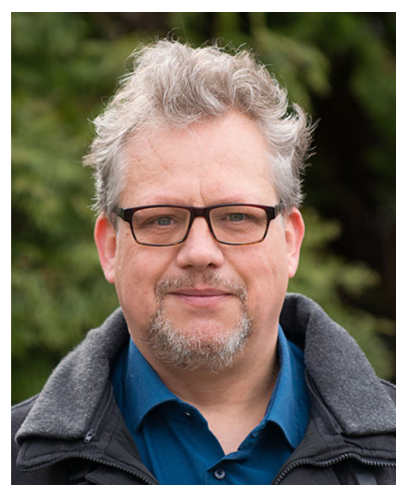

Henrich Frielinghaus studied physics at the RWTH Aachen, and performed a diploma and a $\mathrm{PhD}$ thesis in neutron scattering at the Forschungszentrum Jülich. He did a postdoc at the Risø National Laboratory in Denmark, and became Instrument Responsible for the SANS instrument KWS2 in Jülich that moved to the FRM2, Garching in 2006 (later KWS1). At the newly founded Heinz Maier-Leibnitz Zentrum in Garching, he coordinates the Soft Matter activities and the suite of SANS instruments operated by Jülich. Henrich Frielinghaus is married and has two children. 